\title{
Getting approval for new therapeutic medical devices versus drugs: are the differences justified?
}

\author{
Maria Frigerio \\ Affiliation: “A. DeGasperis” CardioCenter, Niguarda Great Metropolitan Hospital, Milan, Italy. \\ Correspondence: Maria Frigerio, “A. DeGasperis” CardioCenter, Niguarda Hospital, Piazza Ospedale \\ Maggiore 3, 20162 Milan, Italy. E-mail: maria.frigeriodospedaleniguarda.it
}

0 @ERSpublications

Lessons learned from cardiology: the process for approval of medical therapeutic devices must be redesigned http://ow.ly/bJPm3017ySH

In the so-called evidence-based medicine $(\mathrm{EBM})$ era, pre-market clinical trials showing equivalent or superior benefit from new drugs versus existing therapies are required by regulatory bodies, while the process for approval of medical devices is less stringent [1]. The expansion of device-based therapies for cardiovascular conditions makes cardiology the ideal setting for analysing the peculiarities of this process [2].

In the USA, the Food and Drug Administration evaluates both drugs and medical devices; for the latter, some clinical benefit in terms of symptoms, functional status and outcome must be demonstrated in order to obtain Pre-Market Approval (PMA). The amount and quality of data on clinical use required for PMA are greater for high-risk (level III) medical devices, such as implantable cardiac devices (e.g. Mitraclip (Abbott Vascular, Menlo Park, CA, USA), a device for percutaneous correction of mitral valve regurgitation discussed by TARRICONE et al. [3] in this issue of the European Respiratory Review) or those intended for delivering interventional therapies (e.g. the equipment for introducing and positioning Mitraclip). Post-market comparative studies and/or registries are also required in many cases, for surveillance of outcomes and adverse events in the clinical arena. In any case, the process may be regarded as too slow and demanding to allow timely access to innovation, or too fast and superficial to guarantee transparency, safety and appropriate use of resources [4].

In Europe, new drugs are approved by the European Medicines Agency, while medical devices follow a process that is closer to that of a washing machine, lawn mower or video games console than to that of drugs: as for nonmedical appliances, medical devices must obtain the CE mark. Implantable and interventional devices are considered critical, and safety is considered a priority (i.e. their use must not imply unacceptable harm or danger). Regarding efficacy, well-documented animal experiments and a few cases in humans, plus detailed technical documents, may be sufficient to provide "proof of concept" (i.e. the device works as intended by the producer) $[1,2]$. After the CE mark has been obtained, authorisation for clinical use is a matter for national governments and may result in different decisions across countries, as happened for the Mitraclip, which has been approved, for example, in Italy and in Spain but not in the UK or Austria [3]. If the new device is approved, the expected benefits, risks and alternative options must be illustrated to patients so that they are able to choose whether to give their consent, as for any interventional or surgical therapy. However, within an experimental study, the uncertainty about the new therapy is explicit, while it may remain ambiguous once the same therapy is delivered and reimbursed as a standard of care. Within an universal

Received: April 212016 | Accepted after revision: May 242016

Conflict of interest: Disclosures can be found alongside this article at err.ersjournals.com

Provenance: Submitted article, peer reviewed.

Copyright OERS 2016. ERR articles are open access and distributed under the terms of the Creative Commons Attribution Non-Commercial Licence 4.0. 
healthcare system, as in Italy and in many European Union countries, we could say that regulatory bodies allow the doctors to deliver what are indeed experimental therapies, which all citizens are paying for while neither the patients nor the citizens are aware of it, and we, the doctors, seem like we do not care.

In fact, since both in Europe and in the USA, adequately powered pre-market comparative studies showing a positive impact on relevant clinical end-points are not required, clinical benefits are expected, rather than demonstrated, when a new device-based therapy is approved for clinical use.

A point in favour of prompt commercialisation of innovative devices is that pre-market conduct of large clinical trials could be unsustainable for many enterprises: while large pharmaceutical companies may develop new molecules utilising the revenues of already approved drugs, new devices are not infrequently invented and initially developed by small/medium enterprises, focused on that single project, which is time consuming and resource demanding [3]. As a consequence, most clinical studies on new device-based therapies are performed after their commercialisation [4]. Applying the EBM principles, if the positive findings of initial studies would not be confirmed by randomised clinical trials (RCTs), the effectiveness of the new device should be considered, at best, questionable. Conversely, doubts have been raised on the appropriateness and reliability of RCTs for evaluating medical devices [2,3]. First, most of the times these studies are unblinded for both the medical staff and the patient; patient blinding would imply "sham" procedures, which may be considered unethical in several settings. Second, for device-based therapies, randomisation is not easily accepted by the patients or by the physicians: patients who are felt to be in need of new opportunities beyond established therapies and/or those who are perceived as ideal candidates are streamlined to the new treatment. However, little effort is spent randomising patients in whom the risk-benefit profile is presumably less favourable,

TABLE 1 Randomised clinical trials on device-based therapies for cardiovascular conditions

\begin{tabular}{|c|c|c|c|}
\hline Condition & Study treatment & Trial(s); sample size [ref.] & Primary end-point(s); main results \\
\hline Heart failure, LVEF $<35 \%$, LBBB, QRS $>120 \mathrm{~ms}$ & CRT $\pm I C D$ versus MT & CARE-HF, COMPANION & $\begin{array}{l}\text { Death, heart failure } \\
\text { hospitalisations; CRT better }\end{array}$ \\
\hline Refractory heart failure, ineligible for HTx & LVAD versus MT & REMATCH; 129 pts [8] & Death; LVAD better \\
\hline Aortic stenosis, ineligible for surgery & TAVI versus MT & PARTNER B; 358 pts [9] & Death; TAVI better \\
\hline Aortic stenosis, high surgical risk & TAVI versus surgical AVR & $\begin{array}{l}\text { PARTNER A, CORE-VALVE } \\
\text { US; 1500 pts [10] }\end{array}$ & Death; no significant differences \\
\hline $\begin{array}{l}\text { Degenerative/ functional mitral regurgitation, } \\
\text { eligible for surgery }\end{array}$ & $\begin{array}{l}\text { Percutaneous repair }{ }^{\#} \text { versus } \\
\text { surgical treatment }\end{array}$ & EVEREST II; 279 pts [11] & $\begin{array}{l}\text { Death or late MV surgery; surgical } \\
\text { treatment better } \\
\text { (no differences for death) }\end{array}$ \\
\hline Drug-resistant hypertension & $\begin{array}{l}\text { Renal artery denervation } \\
\text { versus MT, open }\end{array}$ & $\begin{array}{l}\text { Symplicity HTN-2; } 106 \text { pts } \\
\text { [13] }\end{array}$ & $\begin{array}{l}\text { BP reduction; renal artery } \\
\text { denervation better }\end{array}$ \\
\hline Drug-resistant hypertension & $\begin{array}{l}\text { Renal artery denervation } \\
\text { versus MT, patient blinded }\end{array}$ & $\begin{array}{l}\text { Simplicity HTN-3, } \\
\text { DENERHTN; } 2000 \text { pts [13] }\end{array}$ & $\begin{array}{l}\text { BP reduction; no significant } \\
\text { differences }\end{array}$ \\
\hline
\end{tabular}

Only some randomised, concluded and published clinical trials are reported as examples. Reference citations are to original individual trial reports, or to comments, reviews, meta-analyses or pooled data analyses. However, table 1 summarises the results of individual trials, not of meta-analysis or pooled data analyses. Synthetic reporting may imply some approximations. STEMI: ST segment elevation myocardial infarction; LVEF: left ventricular ejection fraction; LBBB: left bundle branch block; HTx: heart transplant; AF: atrial fibrillation; PFO: patent foramen ovale; TIA: transient ischaemic attack; PCI: percutaneous coronary intervention; MT: medical therapy; pt: patient; MI: myocardial infarction; ICD: implantable cardioverter-defibrillator; MADIT: Multicenter Automatic Defibrillator Implantation Trial; COMPANION: Comparison of Medical Therapy, Pacing, and Defibrillation in Heart Failure; SCD-HeFT: Sudden Cardiac Death in Heart Failure Trial; CRT: cardiac resynchronisation therapy; CARE-HF: Cardiac Resynchronization - Heart Failure; RAFT: Resynchronization-Defibrillation for Ambulatory Heart Failure Trial; LVAD: left ventricular assist device; REMATCH: Randomized Evaluation of Mechanical Assistance for the Treatment of Congestive Heart Failure; TAVI: transcatheter aortic valve implantation; PARTNER: Placement of Aortic Transcatheter Valves; AVR: aortic valve replacement; EVEREST: Endovascular Valve Edge-to-Edge Repair Study; MV: mitral valve; PC trial: Clinical Trial Comparing PFO Using the Amplatzer PFO Occluder with Medical Treatment in Patients with Cryptogenic Embolism; RESPECT: Randomized Evaluation of Recurrent Stroke Comparing PFO Closure to Established Current Standard of Care Treatment; BP: blood pressure. \#: mitral regurgitation repair with MitraClip device [3]. 
taking also into account that most of the risks of device-based therapies are front-loaded. As a consequence, once a new therapy is approved for clinical use and reimbursed, enrolment into post-market RCTs may be slow and misdirected to patients who are not representative of the true intended target population. Third, the success or failure of device-based therapies depends, in part, on the experience and technical skills of the staff; thus, in clinical practice, patient outcomes could be better or worse than observed in the experimental setting. When single studies suggest some benefit without reaching statistical significance, meta-analysis can be of help but methodological and interpretative differences may lead to discordant conclusions [5]. Meta-analyses gather existing evidences but do not build new knowledge and their value should not be overestimated. Observational studies, in the form of registries or case-control studies, could be more appropriate than RCTs for reflecting clinical outcomes of device-based therapies in the "real-world" setting [2-4] but selection bias may amplify the benefits of interventional therapies with respect to comparative studies.

Nevertheless, looking at the abundant literature on device therapy for various cardiovascular diseases, it seems that in several conditions, RCTs not only are possible but also provide consistent results, either succeeding or failing to demonstrate superiority or noninferiority of new devices to currently available therapeutic options, which could consist of medical or surgical treatments, or other device-based therapies. Table 1 summarises just some examples of the variety of settings and conditions that have been challenged. RCTs provided good evidence supporting the use of implantable cardioverter-defibrillators for primary prevention of sudden death in patients with heart failure and chronic left ventricular dysfunction [7]. However, RCTs of renal artery denervation for refractory hypertension were inconclusive [14]. Moreover, it must be recognised that not all statistically significant benefits are equally relevant and clinically meaningful. For example, transcatheter ablation of atrial fibrillation reduces or delays the recurrence of the arrhythmia with respect to medical therapy alone but it has not been demonstrated so far that this procedure also implies a significant reduction of hard end-points such as stroke, heart failure or death. Consequently, the European Society of Cardiology guidelines provide general recommendations and introduce patients' preferences into the decision making process [15]. As a result, the numbers and rates of atrial fibrillation ablation procedures show a remarkable variability across countries, regions and centres operating within the same healthcare system $[16,17]$. This variability is probably related to differences in cardiologists' opinions more than in epidemiology or patients' choices [15-17]. In Europe, the diagnosis-related group (DRG) reimbursement ranges from about $€ 3700$ in Italy to more than $€ 13000$ in Switzerland [18]. A low DRG tariff may function as a "gatekeeper", limiting the costs for the healthcare system at the expense of the providers and/or of the number of the potential beneficiaries.

In summary, there is the need to rethink the pathway for promoting, evaluating and approving new discoveries and innovative therapies, either pharmacological or device based, and this process has begun. First, building reliable evidence is equally important for both drugs and medical devices; thus, they both should be evaluated and, ultimately, reimbursed within a publicly funded healthcare system, on the basis of efficacy and safety, beyond pure "functioning". Second, the opportunities offered by information and communication technology for conducting high-quality observational research on large patient cohorts should be explored [19], to help in identifying which factors and clusters of factors characterise the need for new therapies, and their risks and benefits according to patient profiles.

Third, public investments could contribute to pre-market research on new devices: the related expenses would probably be compensated by avoiding reimbursement for therapies in the absence of any substantial demonstration of benefit. Moreover, having the financial leverage, the community, through their representatives, researchers, clinicians, and patients' and citizens' associations, could participate in defining research, care and assistance priorities [20]. In the pre-market setting, both patients and physicians could be more prone to admit uncertainty and, consequently, to accept randomisation when feasible. When it is felt impossible or inappropriate, well structured and surveyed registries, including baseline characteristics that guided patient selection and follow-up data, should be mandatory for any innovative procedure. In addition, also regarding drug therapy, the scientific community is in search of alternative pathways for building evidence, especially in complex or difficult situations that do not fit within the classic RCT model (e.g. in the intensive care setting), when a specific strategy (and not a single drug) is under evaluation and may change according to individual patient course [21].

\section{References}

1 Sorenson C, Drummond M. Improving medical device regulation: the United States and Europe in perspective. Milbank Q 2014; 92: 114-150

2 Zannad F, Stough WG, Piña IL, et al. Current challenges for clinical trials of cardiovascular medical devices. Int $J$ Cardiol 2014; 175: 30-37.

3 Tarricone R, Boscolo PR, Armeni P. What type of clinical evidence is needed to assess medical devices? Eur Respir Rev 2016; 25: 259-265.

4 Rajan PV, Kramer DB, Kesselheim AS. Medical device postapproval safety monitoring. Where does the United States stand? Circ Cardiovasc Qual Outcomes 2015; 8: 124-131. 
Kent DM, Dahabreh IJ, Ruthazer R, et al. Device closure of patent foramen ovale after stroke. Pooled analysis of completed randomized trials. J Am Coll Cardiol 2016; 67: 907-917.

6 Keeley EC, Boura JA, Grines CL, et al. Device closure of patent foramen ovale after stroke. Pooled analysis of completed randomized trials. Lancet 2003; 361: 13-20.

7 Woods B, Hawkins N, Mealing S. Individual patient data network meta-analysis of mortality effects of implantable cardiac devices. Heart 2015; 101: 1800-1806.

8 Rose EA, Gelijns AC, Moskowitz AJ, et al. Long-term use of a left ventricular assist device for end-stage heart failure. N Engl J Med 2001; 345: 1435-1443.

9 Kapadia SR, Leon MB, Makkar RR, et al. 5-year outcomes of transcatheter aortic valve replacement compared with standard treatment for patients with inoperable aortic stenosis (PARTNER 1): a randomised controlled trial. Lancet 2015; 385: 2485-2491.

10 Biondi-Zoccai G, Peruzzi M, Abbate A, et al. Network meta-analysis on the comparative effectiveness and safety of transcatheter aortic valve implantation with CoreValve or Sapien devices versus surgical replacement. Heart Lung Vessel 2014; 6: 232-243.

11 Feldman T, Kar S, Elmariah S, et al. Randomized comparison of percutaneous repair and surgery for mitral regurgitation: 5-year results of EVEREST II. J Am Coll Cardiol 2015; 66: 2844-2854.

12 Wynn GJ, Das M, Bonnett LJ, et al. Efficacy of catheter ablation for persistent atrial fibrillation: a systematic review and meta-analysis of evidence from randomized and nonrandomized controlled trials. Circ Arrythm Electrophysiol 2014; 7: 841-852.

13 Taddei S, Dal Canto E, Bruno RM, et al. Renal denervation for resistant hypertension: no. Int Emerg Med 2016; 11: 495-498.

14 Gulati R, Raphael CE, Negoita M, et al. The rise, fall, and possible resurrection of renal denervation. Nat Rev Cardiol 2016; 13: 238-244.

15 Camm AJ, Lip GYH, DeCaterina R, et al. 2012 focused update of the ESC Guidelines for the management of atrial fibrillation. Europace 2012; 14: 1385-1413.

16 Sinner MF, Piccini JP, Greiner MA, et al. Geographic variation in the use of catheter ablation for atrial fibrillation among Medicare beneficiaries. Am Heart J 2015; 169: 775-782.e2.

17 Rihai S, Arbelo E, Brugada J, et al. Regional differences in referral, procedures, and outcome after ablation for atrial fibrillation in Europe: a report from the Atrial Fibrillation Ablation Pilot Registry of the European Society of Cardiology. Europace 2016; 18: 191-200.

18 Cappato R. L'Ablazione Transcatetere della Fibrillazione Atriale in Italia [Transcatheter ablation of atrial fibrillation in Italy]. www.salute.gov.it/portale/temi/documenti/dispositiviMedici/conferenza/34.pdf

19 Mayer-Schonberger V. Big data for cardiology: novel discovery? Eur Heart J 2016; 37: 996-1001.

20 Hunter NL, O'Callaghan KM, Califf RM. Engaging patients across the spectrum of medical product development. View from the US Food and Drug Administration. JAMA 2015; 314: 2499-2500.

21 Califf RM, Sugarman J. Exploring the ethical and regulatory issues in pragmatic clinical trials. Clin Trials 2015; 12: 436-441. 